\title{
A study of the controlled degradation of polypropylene containing pro-oxidant agents
}

\author{
Celso Luis de Carvalho*, Alexandre F Silveira and Derval dos Santos Rosa
}

\begin{abstract}
Intentional degradation by pro-oxidant agents, many of which are metal-based, can result in uncertainty as to the time of biodegradation. Polyacetal (POM) is a thermoplastic polymer commercially classified as an engineering polymer and contains carbon, hydrogen and oxygen. The depolymerization of POM during processing can enhance thermal decomposition. The aim of this study was to investigate the controlled degradation of polypropylene induced by the degradation of POM or $\mathrm{d}_{2} \mathrm{w}^{\otimes}$. Mixtures of polypropylene containing different concentrations of POM or $\mathrm{d}_{2} \mathrm{w}^{\circledast}$ were prepared by extrusion. The properties of the mixtures (blends) were evaluated based on the melt index (MFI), tensile properties, Fourier transform infrared spectroscopy (FTIR), Time inductive oxidation (OIT) and Thermogravimetric analysis (TGA). The two additives (POM and $\mathrm{d}_{2} \mathrm{w}^{\circledast}$ ) enhanced the oxidative thermal degradation of polypropylene and the degradation of the polypropylene/POM mixture could be controlled by altering the POM concentration.
\end{abstract}

Keywords: Degradation; Oxidizing; Polypropylene; Polyacetal

\section{Introduction}

Packaging waste accounted for 78.81 million tons or 31.6\% of municipal solid waste (MSW) in the United States in 2003, 56.3 million tons or 25\% of MSW in Europe in 2005, and 3.3 million tons or 10\% of MSW in Australia in 2004 . In the US, the predominant method of waste disposal is currently landfill packaging, followed by recycling, composting and incineration (Kale et al. 2007). Commodity polymers (polyethylene PE, polypropylene PP, polystyrene PS, polyvinyl chloride PVC and polyethylene terephtalate PET) prevail in packaging applications (PlasticsEurope 2011) and polyolefins are increasingly being used in new applications (Gahleitner 2011). An excellent way of producing degradable polyethylene is to mix this polymer with pro-oxidant additives that can effectively improve the degradability of these materials (Roy et al. 2007). Intentional degradation by pro-oxidant agents, many of which are metal-based (Roy et al. 2007), has generated uncertainties in the evaluation of biodegradation (European Bioplastics 2012) and several surveys it is claimed that polyolefins (PE, PP) is an inert polymer with good resistance to microorganisms (Albertsson 1978, 2003). The controlled degradation of polypropylene has been used

\footnotetext{
*Correspondence: clc.celso@gmail.com

Universidade Federal do ABC - UFABC, Av do Estado, 5001, Santo André, SP, Brazil
}

in rheological control by distributing and reducing the molar mass of organic peroxides in reactive extrusion (Rocha et al. 1994; Kim 1996). Polyacetal (POM) is a thermoplastic polymer that is susceptible to thermal decomposition (depolymerization) (Cottin et al. 2000). The objective of this study was to investigate the controlled degradation of polypropylene induced by the degradation of an organic oxidizing agent (POM) in extrusion. The additive $\mathrm{d}_{2} \mathrm{w}^{\circ}$, a commercial metal-based pro-oxidant, was used for comparison.

\section{Materials and methods \\ Materials}

Isotactic polypropylene (iPP) H603 (density: $0.905 \mathrm{~g} / \mathrm{cm}^{3}$; MFI: $1.5 \mathrm{~g} / 10 \mathrm{~min}$ ) was used in granulated form, as supplied by Braskem (Triunfo, RS, Brazil). The polyacetal copolymer (density: $1.42 \mathrm{~g} / \mathrm{cm}^{3}$; MFI: $14.0 \mathrm{~g} / 10 \mathrm{~min}$ ) was used in powder form as supplied by Ticona (São Paulo, SP, Brazil). The commercial pro-oxidant additive $\mathrm{d}_{2} \mathrm{w}^{\bullet}$ was supplied by RES Brazil (São Paulo, SP, Brazil).

\section{Methods \\ Preparation of the mixtures}

The additive $\mathrm{d}_{2} \mathrm{w}^{\circ}$ was incorporated in granular form and POM in powder form. The incorporation of POM or $d_{2} w^{\circ}$ into polypropylene (PP) initially involved homogenization

\section{黑 Springer}


Table 1 The polymer/additive mixtures used in this study

\begin{tabular}{lccccccc}
\hline Code & $\mathrm{PP}$ & $\mathrm{POM}$ & $\mathbf{d}_{\mathbf{2}} \mathbf{w}^{*}$ & Code & $\mathrm{PP}$ & $\mathrm{POM}$ & $\mathbf{d}_{\mathbf{2}} \mathbf{w}$ \\
\hline $\mathrm{PP}_{1}$ & $100^{*}$ & $0^{*}$ & $0^{*}$ & $\mathrm{PP}_{5}$ & 100 & 0 & 2 \\
$\mathrm{PP}_{2}$ & 100 & 1 & 0 & $\mathrm{PP}_{6}$ & 100 & 3 & 0 \\
$\mathrm{PP}_{3}$ & 100 & 0 & 1 & $\mathrm{PP}_{7}$ & 100 & 0 & 3 \\
$\mathrm{PP}_{4}$ & 100 & 2 & 0 & $\mathrm{PP}_{8}$ & 100 & 10 & 0 \\
\hline
\end{tabular}

$\left(^{*}\right)$ Amount expressed in parts per hundred of resin (phr).

in Drais with a load capacity of $\sim 100 \mathrm{~g}$ of material. The mixing time was $\sim 30 \mathrm{~s}$. Blends of PP with POM or $\mathrm{d}_{2} \mathrm{w}^{\odot}$ were prepared as shown in Table 1 using a single screw extruder fitted with a $25 \mathrm{~mm}$ diameter screw, a heating cylinder with an L/D ratio of 25:1 and four wire screens in series $(60,150,150$ and 100 mesh) to maximize the homogeneity. The extrusion conditions were $220^{\circ} \mathrm{C}$, $250^{\circ} \mathrm{C}$ and $250^{\circ} \mathrm{C}$ for the first, second and third zones, respectively.

\section{Analysis}

\section{Melt flow index (MFI)}

The MFI was determined in a plastometer (model 7023.000, CEAST, Ohio, USA) according to ASTM D-1238 (ASTM 2004). The test conditions were set at a load of $2,160 \mathrm{~kg}$ and a temperature of $230^{\circ} \mathrm{C}$ for all mixtures.

\section{Mechanical tests}

Type IV specimens (ASTM D-638-10) (ASTM 2010) were injected into a model PIC-BOY 22 machine (Petersen \& Cia Ltda, São Paulo, SP, Brazil) with an injection capacity of $22 \mathrm{~g}$ of polystyrene. The total cycle time was $30 \mathrm{~s}$ and the temperatures of zones 1 (injection nozzle), 2 and 3 were $220^{\circ} \mathrm{C}, 220^{\circ} \mathrm{C}$ and $180^{\circ} \mathrm{C}$, respectively. The tensile test was done in a universal testing machine (model 5569, Instron), according to ASTM D638-10, at a test speed of
$25 \mathrm{~mm} / \mathrm{min}$ and cell load of $50 \mathrm{kN}$. The tensile strength at break and elastic modulus were determined.

\section{Fourier transform infrared spectroscopy (FTIR)}

Films $30 \pm 2 \mu \mathrm{m}$ thick were prepared at $190^{\circ} \mathrm{C}$ with a compression pressure of 2000 psi and compression time of 80 s. FTIR measurements were obtained using a Varian 660-IR FT-IR spectrometer operated in transmittance mode. Thirty-two scans were obtained in triplicate from $4000 \mathrm{~cm}^{-1}$ to $400 \mathrm{~cm}^{-1}$ at a resolution of $4 \mathrm{~cm}^{-1}$. The influence of POM and $\mathrm{d}_{2} \mathrm{w}^{\odot}$ on polypropylene oxidation was determined from the spectra by calculating the carbonyl (CI) and hydroxyl (HI) indices based on the relationships $\mathrm{CI}=\mathrm{A}_{1725} / \mathrm{A}_{2722}$ and $\mathrm{HI}=\mathrm{A}_{3500} / \mathrm{A}_{2722}$, respectively.

\section{Differential scanning calorimetry (DSC)}

DSC was done in a TA Instruments calorimeter at a nitrogen flow of $50 \mathrm{ml} / \mathrm{min}$. Approximately $10 \mathrm{mg}$ of each sample was heated, cooled and heated again over a temperature range of $25-250^{\circ} \mathrm{C}$ at a heating and cooling rate of $10^{\circ} \mathrm{C} / \mathrm{min}$. The melting temperature $(\mathrm{Tm})$, crystallization temperature (Tc) and degree of crystallinity were calculated using the enthalpy of fusion values of $209 \mathrm{~J} \cdot \mathrm{g}^{-1}$ and $306 \mathrm{J.g}{ }^{-1}$ for $100 \%$ crystalline polypropylene and polyacetal, respectively (Canevarolo 2003; Kumar et al. 1995).

\section{Oxidation induction time (OIT)}

The OIT was determined by exposing 10 $\mathrm{mg}$ of each mixture to a nitrogen flow of $50 \mathrm{ml} / \mathrm{min}$ and a heating rate of $20^{\circ} \mathrm{C} / \mathrm{min}$. An oxygen flow of $50 \mathrm{ml} / \mathrm{min}$ was used after melting at $200^{\circ} \mathrm{C}$.

\section{Thermogravimetric analysis (TGA)}

TGA was done in equipment from TA Instruments. Approximately $10 \mathrm{mg}$ of each mixture was placed in a

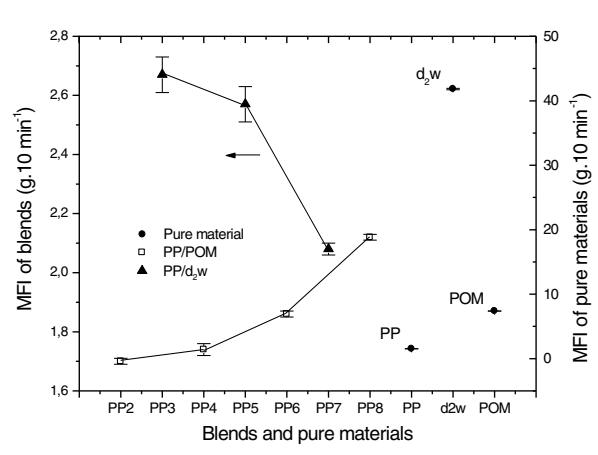

\begin{tabular}{cl}
\hline Blend code & $\mathrm{MFI}(\mathrm{g} / 10 \mathrm{~min})$ \\
\hline $\mathrm{PP}_{1}$ & $1.53 \pm 0.01$ \\
$\mathrm{PP}_{2}$ & $1.70 \pm 0.01$ \\
$\mathrm{PP}_{3}$ & $2.67 \pm 0.06$ \\
$\mathrm{PP}_{4}$ & $1.74 \pm 0.02$ \\
$\mathrm{PP}_{5}$ & $2.57 \pm 0.06$ \\
$\mathrm{PP}_{6}$ & $1.86 \pm 0.01$ \\
$\mathrm{PP}_{7}$ & $2.08 \pm 0.02$ \\
$\mathrm{PP}_{8}$ & $2.12 \pm 0.01$ \\
$\mathrm{~d}_{2} \mathrm{~W}^{\circledast}$ & $41.8 \pm 0.1$ \\
\hline $\mathrm{POM}$ & $7.39 \pm 0.01$
\end{tabular}

Figure 1 MFI for pure materials (PP, POM, $\mathbf{d}_{\mathbf{2}} \mathbf{w}^{\circledast}$ ) and blends (PP/POM, PP/ $\left.\mathbf{d}_{\mathbf{2}} \mathbf{w}^{\circledast}\right)$. The points are the mean \pm SD of 6 determinations. b) Average results and their respective estimated standard deviation of the melt index of the compositions and pure materials. 
nitrogen atmosphere and heated at a rate of $10^{\circ} \mathrm{C} / \mathrm{min}$ over a temperature range of $25-550^{\circ} \mathrm{C}$. The nitrogen flow over the measurement cell was $50 \mathrm{ml} / \mathrm{min}$. The activation energy of degradation (Ea) was determined according to ASTM E1641 (ASTM 2007).

\section{Results and discussion}

\section{Melt flow index (MFI)}

The MFI is inversely related to sample viscosity and can be used to estimate the interaction between the phases in polymer mixtures (Huang et al. 2003). Figure 1 shows that pure PP had the lowest MFI of all samples, indicating that it had the highest viscosity under the test conditions. The MFI increased as the content of POM in the mixtures increased $\left(\mathrm{PP}_{2}, \mathrm{PP}_{4}, \mathrm{PP}_{6}\right.$ and $\left.\mathrm{PP}_{8}\right)$ and probably reflected the immiscibility between the phases $(\mathrm{PP} / \mathrm{POM})$ since the variation in the measurements was proportional to the mass of POM in the PP/POM mixture (blend) (Huang et al. 2003). In polypropylene mixtures $\mathrm{PP}_{3}, \mathrm{PP}_{5}$ and $\mathrm{PP}_{7}$ the flow behavior was reversed, i.e., the MFI decreased as

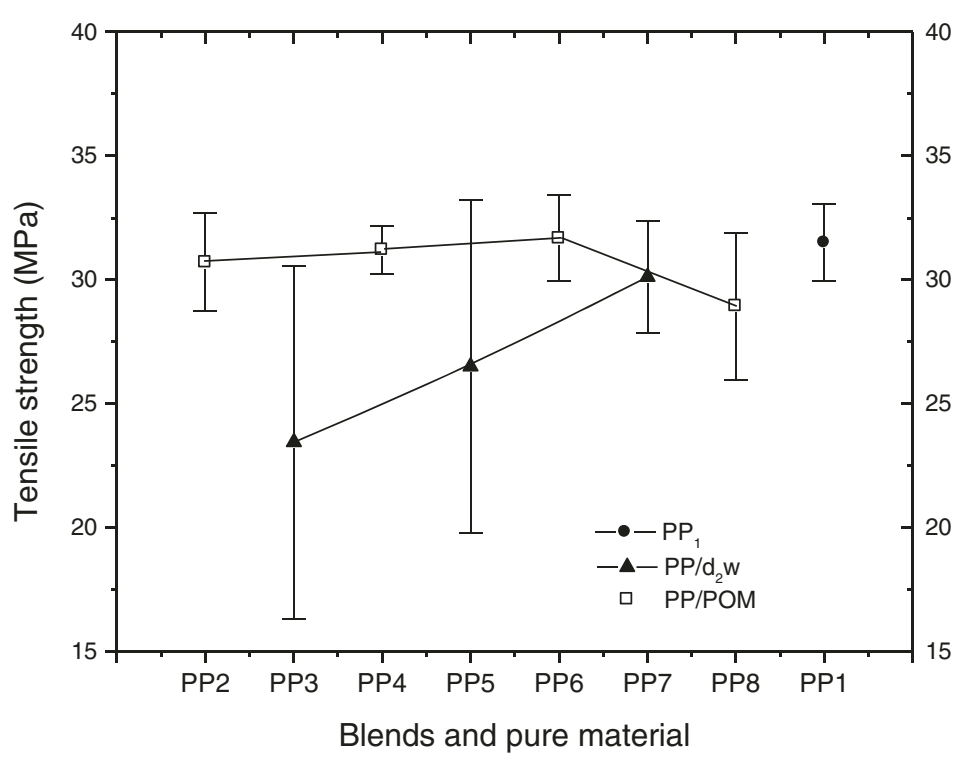

a)

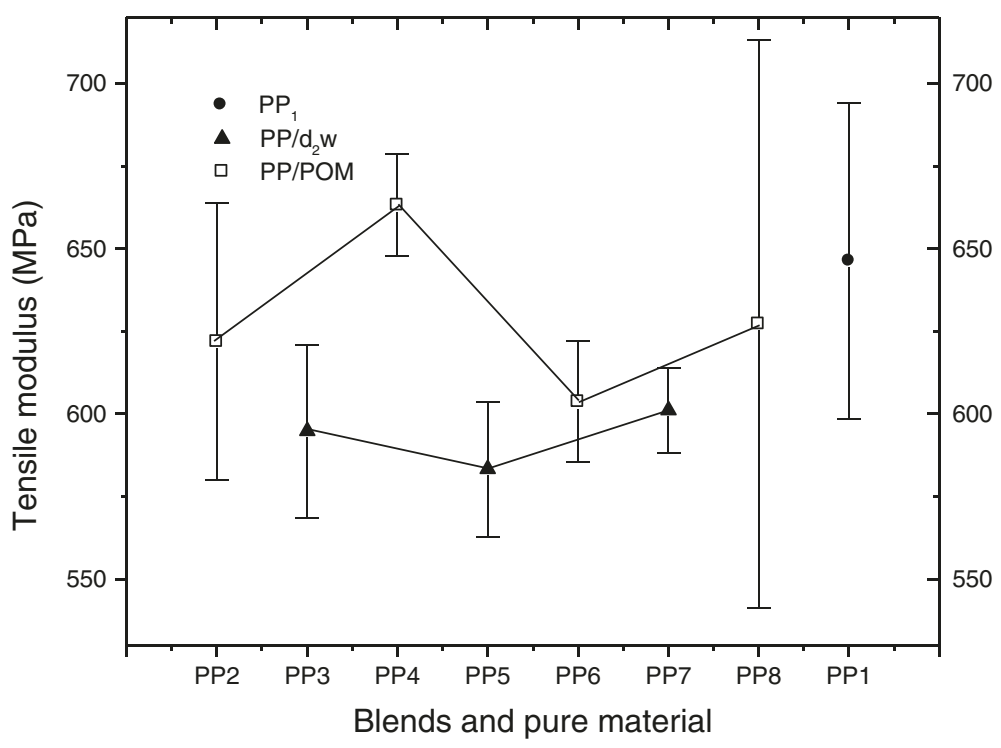

b)

Figure 2 a) Tensile strength and b) elasticity modulus of pure polypropylene $\left(\mathrm{PP}_{1}\right)$ and blends with $\mathrm{POM}$ and $\mathrm{d}_{2} \mathbf{w}^{\circledR}$. The points are the mean \pm SD of 6 determinations. 


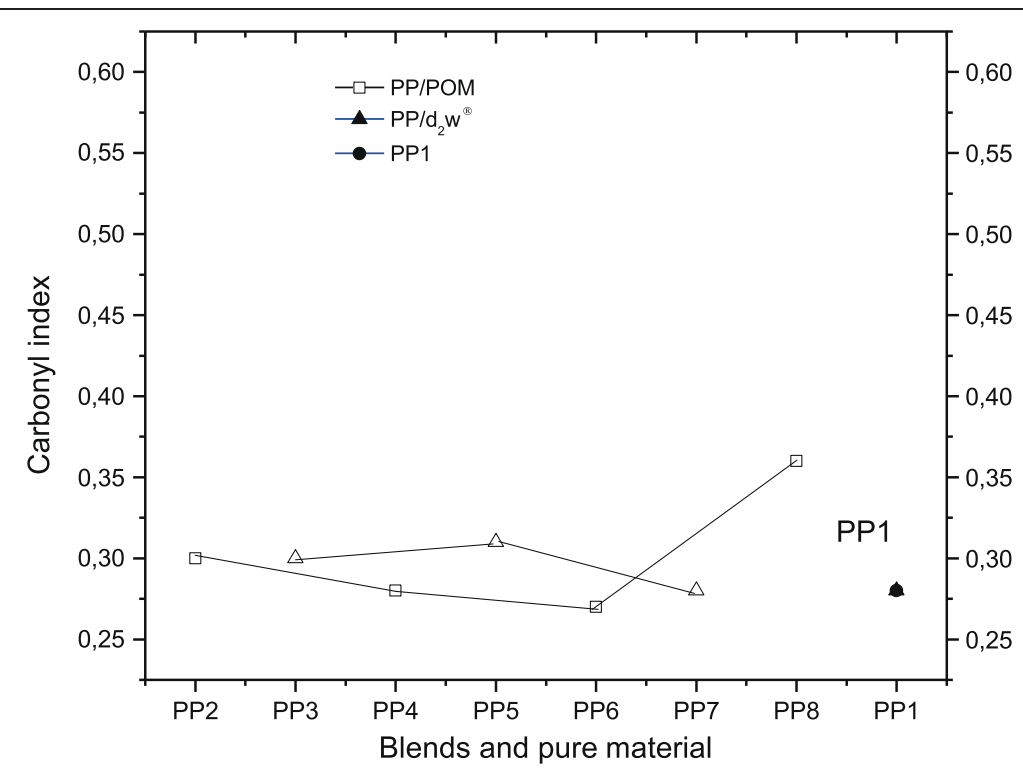

Figure 3 Carbonyl indices of pure material $\left(\mathrm{PP}_{1}\right)$ and $\mathrm{PP} / \mathrm{POM}$ and $\mathrm{PP} / \mathrm{d}_{2} \mathrm{w}^{\circledR}$ blends.

the concentration of $\mathrm{d}_{2} \mathrm{~W}^{\circ}$ increased. Partial miscibility between the vehicle solution for the additive $\mathrm{d}_{2} \mathrm{w}^{\circ}$ and the polypropylene matrix could explain this result, although the possibility of degradation of the matrix and dispersed phase to generate cross-linked additive carrier material (dispersed phase) and polypropylene (matrix) should also be considered (Huang et al. 2003; Waldman and De Paoli 1998; Bouhelal et al. 2010).

\section{Tensile testing}

Figure 2 shows the tensile modulus of elasticity and flow of polypropylene and blends with $\mathrm{d}_{2} \mathrm{w}^{\circ}$ or POM. Mixtures containing $\mathrm{d}_{2} \mathrm{w}^{\circ}$ showed larger standard deviations than those containing POM. This difference probably reflected the degree of dispersion of the additive in the polypropylene matrix since $d_{2} \mathrm{~W}^{\circ}$ was incorporated into polypropylene in granular form while POM was incorporated in powder form. This conclusion suggests interaction between the degradative processes associated with polypropylene and POM during sample preparation. The differences in the tensile strength of the two compositions (Figure 2a) most likely reflect variations in the inherent mechanical strength of the carrier material and the additive $\mathrm{d}_{2} \mathrm{w}^{\circ}$. Likewise, differences in the modulus of elasticity (Figure $2 \mathrm{~b}$ )

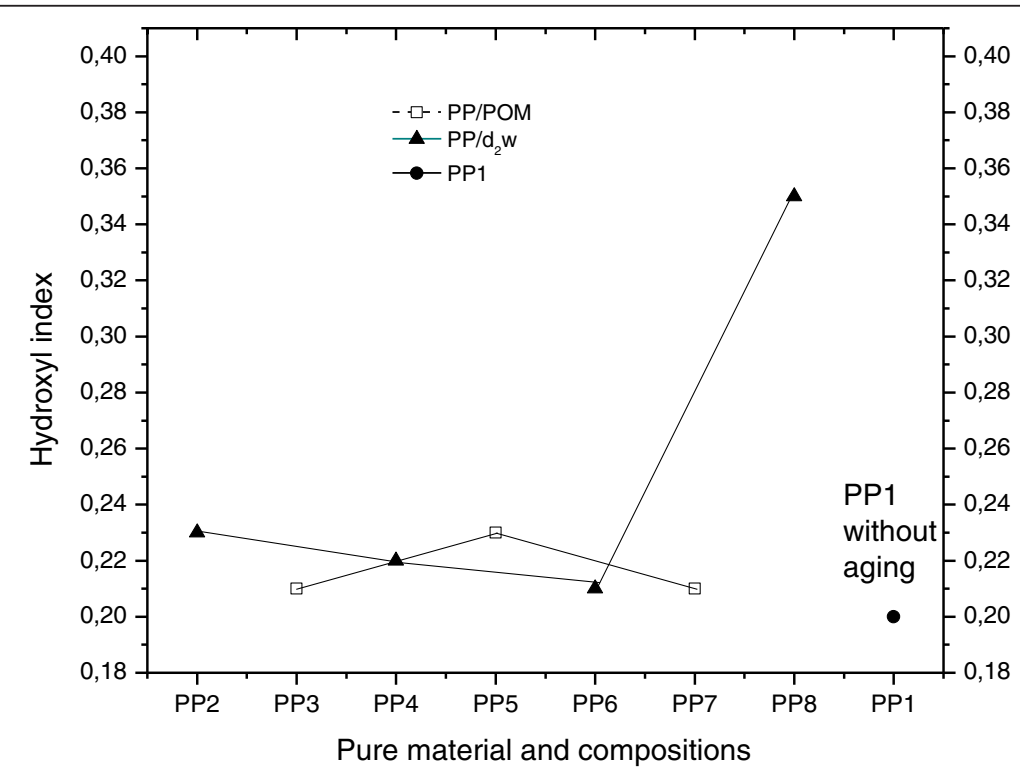

Figure 4 Hydroxyl indices of pure material $\left(\mathrm{PP}_{1}\right)$ and $\mathrm{PP} / \mathrm{POM}$ and $\mathrm{PP} / \mathrm{d}_{2} \mathrm{w}^{\circledast}$ blends before and after thermal aging. 
Table 2 Thermal properties of pure materials $\left(\mathrm{PP}_{1}, \mathrm{POM}\right.$ and $d_{2} w^{\odot}$ ) and blends of PP/POM and PP/ $d_{2} w^{\odot}$

\begin{tabular}{lccccc}
\hline Compositions & $\begin{array}{c}\mathbf{T m} \\
\left({ }^{\circ} \mathbf{C}\right)\end{array}$ & $\begin{array}{c}\Delta \mathbf{H m} \\
(\mathbf{J} / \mathbf{g})\end{array}$ & $\begin{array}{c}\mathrm{Tc} \\
\left({ }^{\circ} \mathbf{C}\right)\end{array}$ & $\begin{array}{c}\Delta \mathbf{H c} \\
(\mathbf{J} / \mathbf{g})\end{array}$ & $\begin{array}{c}\text { Crystallinity } \\
(\%)\end{array}$ \\
\hline $\mathrm{PP}_{1} 100 \%$ & 160.0 & 89.7 & 124.9 & 96.7 & 42.9 \\
$\mathrm{PP}_{2}$ 100/1 & 160.1 & 93.6 & 125.4 & 90.7 & 44.8 \\
$\mathrm{PP}_{3}$ 100/1 & 158.8 & 85.8 & 122.2 & 94.3 & 41.1 \\
$\mathrm{PP}_{4}$ 100/2 & 160.2 & 96.9 & 125.3 & 93.6 & 46.4 \\
$\mathrm{PP}_{5}$ 100/2 & 158.7 & 87.2 & 119.7 & 94.8 & 41.7 \\
$\mathrm{PP}_{6}$ 100/3 & 160.1 & 97.8 & 125.4 & 93.9 & 46.8 \\
$\mathrm{PP}_{7}$ 100/3 & 160.2 & 80.8 & 117.4 & 86.7 & 38.7 \\
$\mathrm{PP}_{8}$ 100/10 & 161.5 & 89.3 & 118.6 & 95.6 & 42.7 \\
$\mathrm{POM}^{100 \%}$ & 165.3 & 138.5 & 142.2 & 136.5 & 42.5 \\
$\mathrm{~d}_{2} \mathrm{~W}^{\otimes} 100 \%$ & 124.1 & 114.3 & 107.5 & 116.5 & - \\
\hline
\end{tabular}

reflect variations in the stiffness of the additive $d_{2} w^{\circ}$ and POM (Huang et al. 2003). The standard deviations for the modulus of elasticity of pure polypropylene and the $\mathrm{PP}_{8}$ mixture were also high. The presence of tiny, randomly distributed bubbles in these two preparations could have contributed to this high standard deviation; differences in the composition of the samples are unlikely to be a cause of this variation.

\section{Infrared spectroscopy (FTIR)}

Absorbance in the region of $1725 \mathrm{~cm}^{-1}$ and $3500 \mathrm{~cm}^{-1}$ indicated the presence of carbonyl and hydroxyl groups (De Paoli 2008; Cáceres and Canevarolo 2009), respectively, and the absorbance peak at $2722 \mathrm{~cm}^{-1}$ was related to angular molecular vibrations in $\mathrm{CH}$ and axial molecular vibrations in $\mathrm{CH}_{3}$, as suggested elsewhere (Cáceres and Canevarolo 2009; Babetto and Canevarolo 2002; Rabello and White 1997; Garton et al. 1978). Comparison of these absorbances can be used to normalize IR spectra since these peaks are insensitive to the oxidative degradation of pure polypropylene (Wang et al. 2011). Figure 3 and Figure 4 show variation in the carbonyl (CI) and hydroxyl (HI) indices, respectively. The $\mathrm{CI}$ index showed increased formation of carbonyls in mixture $\mathrm{PP}_{8}$, whereas $\mathrm{PP}_{3}$ and other mixtures containing $\mathrm{d}_{2} \mathrm{w}^{\circ}\left(\mathrm{PP}_{5}\right.$ and $\left.\mathrm{PP}_{7}\right)$ were quite stable in this parameter. The HI index showed similar behavior to the $\mathrm{CI}$ index shown in Figure 3, but mixture $\mathrm{PP}_{8}$ had high hydroxyl formation, probably indicating greater susceptibility to the formation of $\mathrm{nOH}$ (acetic acid) (Duan et al. 2006) during processing, with absent or low oxygen supply during extrusion of the mixtures and injection of the samples. Together, these results indicate that the addition of $\mathrm{d}_{2} \mathrm{w}^{\circ}$ did not enhance the degradation of polypropylene, whereas the presence of POM resulted in greater thermal degradation of polypropylene that was proportional to the content of POM and greater than the concentration of $\mathrm{POM}$ in mixture $\mathrm{PP}_{6}$ (3\% by weight).

\section{Differential scanning calorimetry (DSC)}

Table 2 shows the thermal properties of the pure materials $\left(\mathrm{PP}_{1}, \mathrm{POM}\right.$ and $\left.\mathrm{d}_{2} \mathrm{w}^{\circ}\right)$ and mixtures (blends) $\left(\mathrm{PP} / \mathrm{d}_{2} \mathrm{w}^{\circ}\right.$ and $\mathrm{PP} / \mathrm{POM})$. Figure 5 and Figure 6 show the crystalline melting temperatures $(\mathrm{Tm})$ and crystallization temperatures (Tc), respectively. There was a trend towards a higher Tm for all mixtures containing POM and $\mathrm{d}_{2} \mathrm{w}^{\circ}$. In mixtures containing $\mathrm{d}_{2} \mathrm{w}^{\circ}\left(\mathrm{PP}_{3}, \mathrm{PP}_{5}\right.$ and $\left.\mathrm{PP}_{7}\right)$ there was a reduction in Tc that was proportional to the $\mathrm{d}_{2} \mathrm{~W}^{\circ}$ concentration, such that the Tc was lower than for pure polypropylene. In $\mathrm{PP} / \mathrm{POM}$ blends $\left(\mathrm{PP}_{2}, \mathrm{PP}_{4}, \mathrm{PP}_{6}\right.$ and $\left.\mathrm{PP}_{8}\right)$ the Tc of $\mathrm{PP}_{2}$, $\mathrm{PP}_{4}$ and $\mathrm{PP}_{6}$ stabilized at $\sim 5^{\circ} \mathrm{C}$ above the Tc of pure

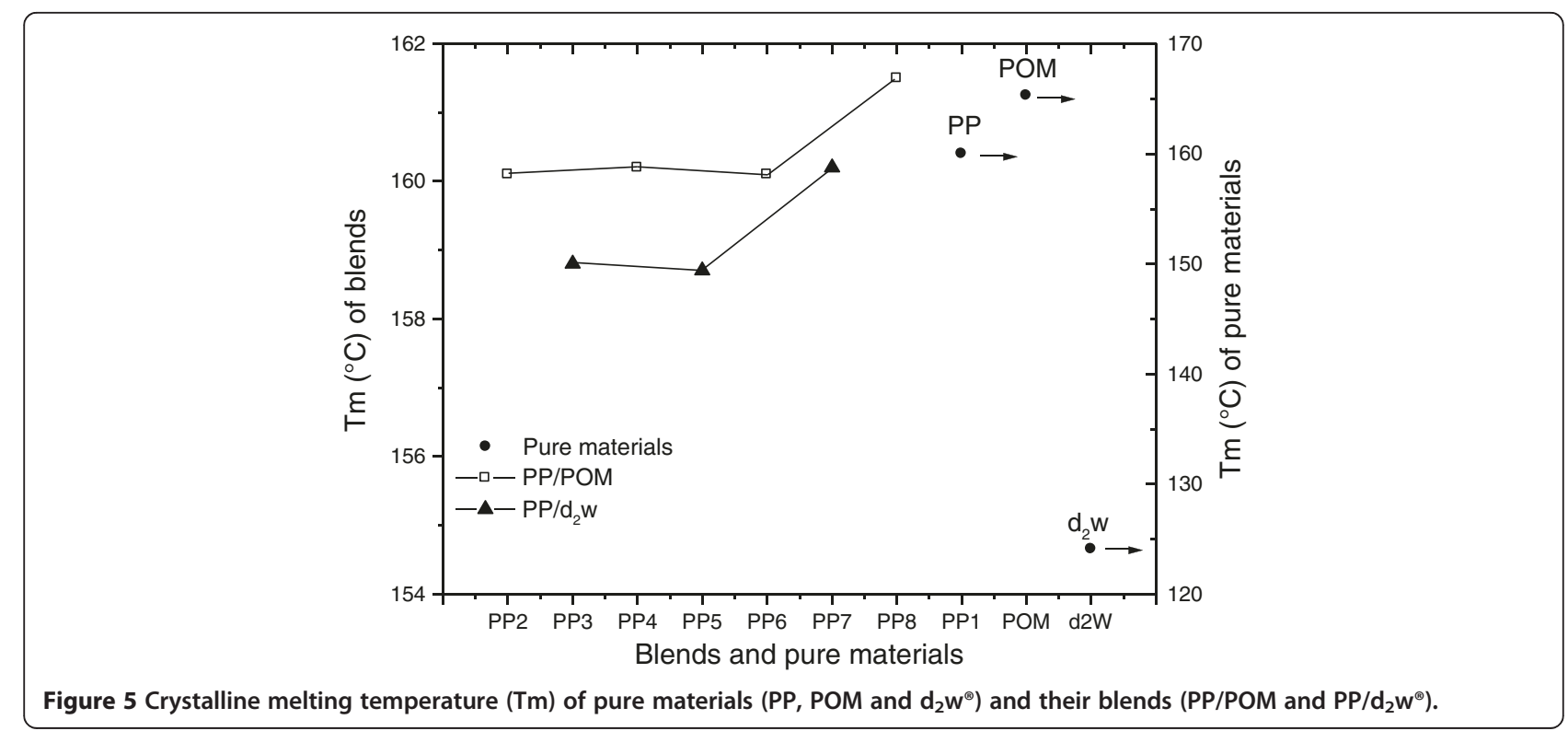




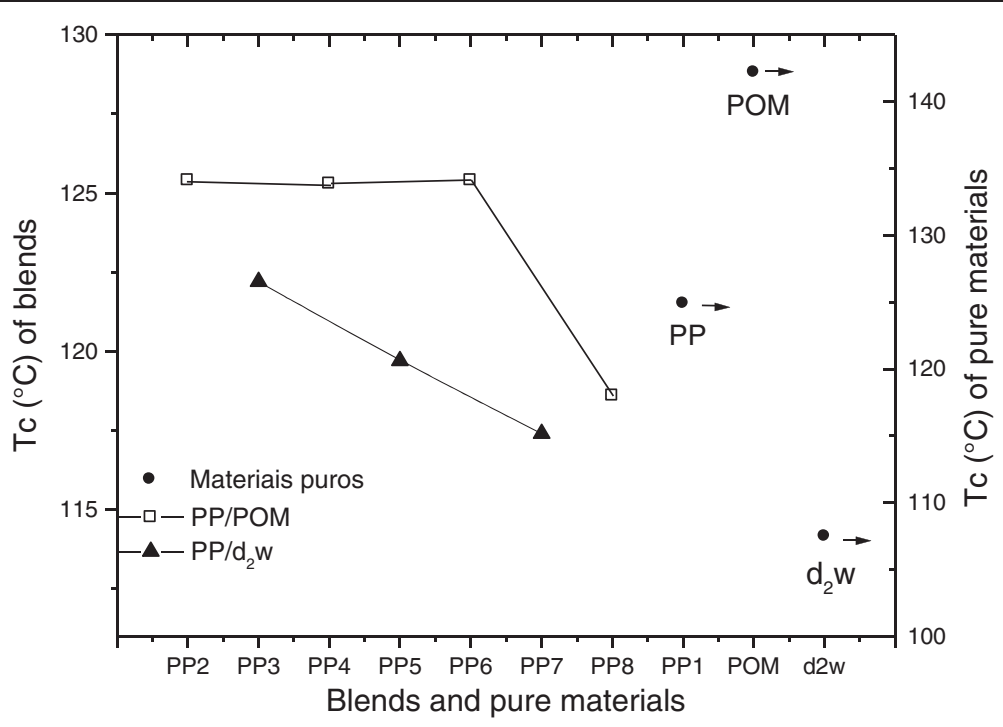

Figure 6 Crystallization temperature (Tc) of the pure materials (PP, POM and $\left.d_{2} w^{\oplus}\right)$ and their blends (PP/POM and PP/d $\mathrm{d}_{2} \mathbf{w}^{\circledast}$ ).

polypropylene. This is a desirable result in processing by injection because it allows a reduction in the cooling time. The Tc of the $\mathrm{PP}_{8}$ blend was lower than for the other mixtures and also in relation to pure POM. This finding suggests that morphological changes in POM are probably the result of its thermal degradation.

Figure 7 and Figure 8 show the heat flux derived from the crystallization of $\mathrm{PP} / \mathrm{POM}\left(\mathrm{PP}_{2}, \mathrm{PP}_{4}, \mathrm{PP}_{6}\right.$ and $\left.\mathrm{PP}_{8}\right)$ and $\mathrm{PP} / \mathrm{d}_{2} \mathrm{w}^{\circ}\left(\mathrm{PP}_{3}, \mathrm{PP}_{5}\right.$ and $\left.\mathrm{PP}_{7}\right)$. Mixtures containing $\mathrm{POM}$ showed additional peaks between the peaks of pure POM and polypropylene. Degradation reactions usually appear as endothermic processes and exothermic behavior is generally a response to depolymerization (Canevarolo 2003;
De Paoli 2008). Indeed, an endothermic response was observed in the curve of the derivative of heat flow during the crystallization of pure POM (Figure 7). The coexistence of these two processes in PP/POM mixtures suggests a change in the Tc and the formation of volatiles that are not detected by thermogravimetric analysis at temperatures below $200^{\circ} \mathrm{C}$. During the crystallization of mixtures of $\mathrm{PP} / \mathrm{d}_{2} \mathrm{w}^{\circ}$ there is no heat flow between the peaks of the pure materials ( $\mathrm{PP}$ and $\mathrm{d}_{2} \mathrm{w}^{\circ}$ ).

\section{Oxidation induction time (OIT)}

The oxidation induction time (OIT) is an accelerated aging test that allows comparison of the relative resistance of

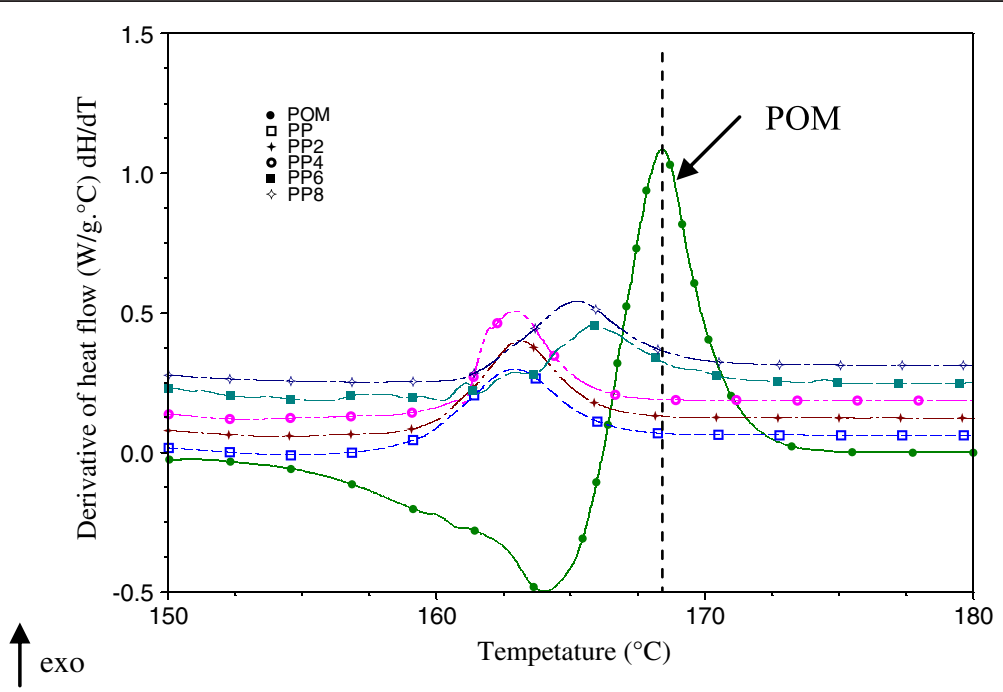

Figure 7 Derivative of heat flow in the crystallization of pure materials $\left(\mathrm{PP}_{1}\right.$ and $\left.\mathrm{POM}\right)$ and $\mathrm{PP} / \mathrm{POM}$ blends $\left(\mathrm{PP}_{2}, \mathrm{PP}_{4}, \mathrm{PP}_{6}\right.$ and $\left.\mathrm{PP} 8\right)$ without thermal aging. 


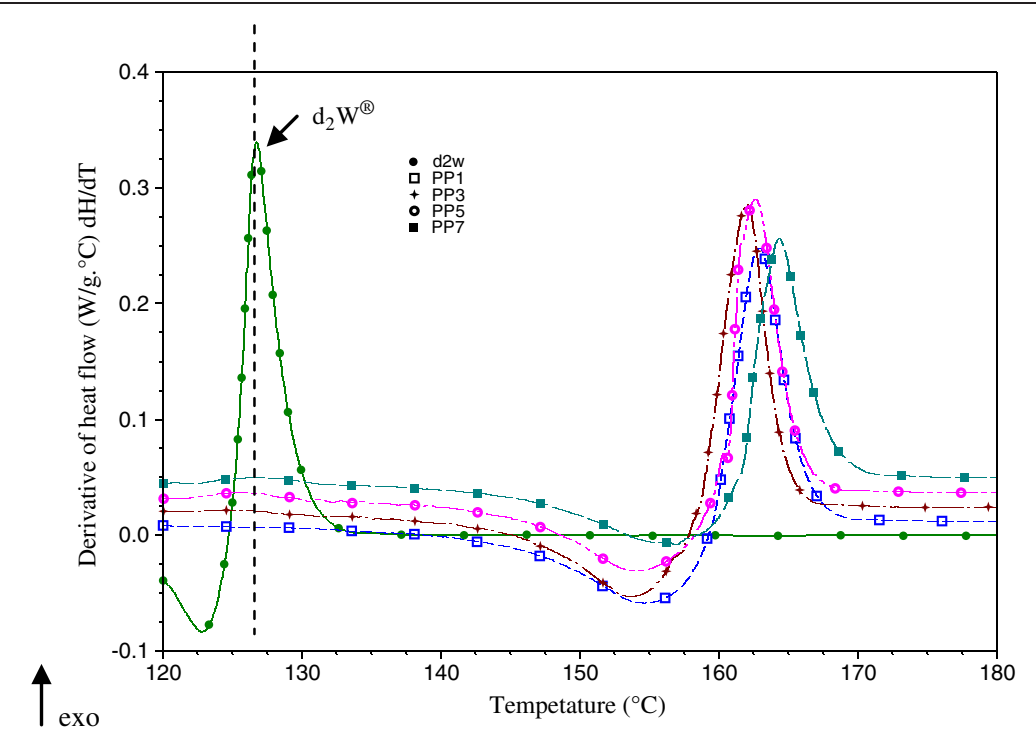

Figure 8 Derivative of heat flow in the crystallization of pure materials $\left(\mathrm{PP}_{1}\right.$ and $\left.d_{2} w^{\circledast}\right)$ and blends of $P P / d_{2} w^{\circledast}\left(P P_{3}, P P_{5}\right.$ and $\left.P P_{7}\right)$ without thermal aging.

materials to thermal oxidation. Table 3 and Figure 9 provide the OIT values for the pure materials and blends studied. The additive $d_{2} w^{\circ}$ accelerated the oxidation of polypropylene in the presence of oxygen. However, there was little change in the OIT values of blends containing different amounts of $\mathrm{d}_{2} \mathrm{w}^{\circ}\left(\mathrm{PP}_{3}, \mathrm{PP}_{5}\right.$ and $\left.\mathrm{PP}_{7}\right)$, i.e., the OIT values essentially reflected the amount of pure additive $\left(\mathrm{d}_{2} \mathrm{w}^{\circ}\right)$ present in the mixtures. This finding indicates that there is little margin for controlling the thermo-oxidation of polypropylene during processing since all samples were processed under the same condition. In addition, changes in morphology arising from processing interfere with the diffusion of volatile degradation products.

In $\mathrm{PP} / \mathrm{POM}$ blends, there was a marked decrease in the OIT values from blend $\mathrm{PP}_{6}$ onwards. In contrast, there was an increase in the OIT values of blends $\mathrm{PP}_{2}$ and $\mathrm{PP}_{4}$, i.e., a stabilizing (antioxidant) effect. A similar delay in the kinetics of degradation was observed in the absence of oxygen in the TGA of these two blends, i.e., the Ti of the blends was greater than that of pure polypropylene $\left(\mathrm{PP}_{1}\right)$. The OIT and TGA results indicated that $\mathrm{d}_{2} \mathrm{w}^{\circ}$ concentrations $\geq 2 \%$ increased the thermal stability of the blends. In the case of POM, there was a decrease in the stabilizing synergistic effect at concentrations up to $3 \%$; at higher concentrations, POM had an oxidizing effect on polypropylene.

Table 3 Oxidation induction time for pure materials and blends

\begin{tabular}{lcccccccccc}
\hline \multicolumn{10}{c}{ Pure materials and blends } \\
\hline & $\mathrm{PP}_{1}$ & $\mathrm{PP}_{2}$ & $\mathrm{PP}_{3}$ & $\mathrm{PP}_{4}$ & $\mathrm{PP}_{5}$ & $\mathrm{PP}_{6}$ & $\mathrm{PP}_{7}$ & $\mathrm{PP}_{8}$ & $\mathrm{~d}_{2} \mathrm{~W}^{\otimes}$ & $\mathrm{POM}$ \\
Time (min) & 4.55 & 5.47 & 1.09 & 5.58 & 1.04 & 4.52 & 1.03 & 1.67 & 1.27 & $<1$ \\
\hline
\end{tabular}

The oxidation of a polymer involves a complex chain of reactions that involves many steps such that the overall Ea is the sum of the energies of activation of individual stages. In this chain of reactions there may be temperature ranges in which deviations from Arrhenius' law can be neglected, e.g., with blends $\mathrm{PP}_{2}$ and $\mathrm{PP}_{4}$. The oxidation of polypropylene (in powder form) has been referred to as nonhomogeneous (heterogeneous) kinetics that is characterized by chemiluminescence (Celina and George 1995). This oxidation is based on a model containing small numbers of localized zones (amorphous regions) in which oxidation occurs at a high rate and from where it spreads to other regions. The presence of stabilizers retards the diffusion of volatile degradation products for a short period of time known as the induction period. Even using sensitive techniques involving photon emission, such as chemiluminescence, the investigation of this phenomenon over such a short timescale is a difficult task, even though the Ea is higher in this period (Celina and George 1993). Several studies (Wang et al. 2011; Bouhelal et al. 2010; Groening and Hakkarainen 2002; Albertsson and Hakkarainen 2008) have shown that the decomposition of hydroperoxides in polypropylene leads to the formation of volatile products and that water is a major product of degradation but does not interfere with the spread of oxidation. During this period, generally only a decrease in polymer molecular mass is observed, along with the formation of volatile, low molecular mass products. Eriksson (Eriksson et al. 2001) suggested that following the formation of peracids by the oxidation of formaldehyde, the spreading of oxidation is favored by the gas phase and that the relatively low reactivity of formaldehyde allows greater diffusion to more distant regions. 


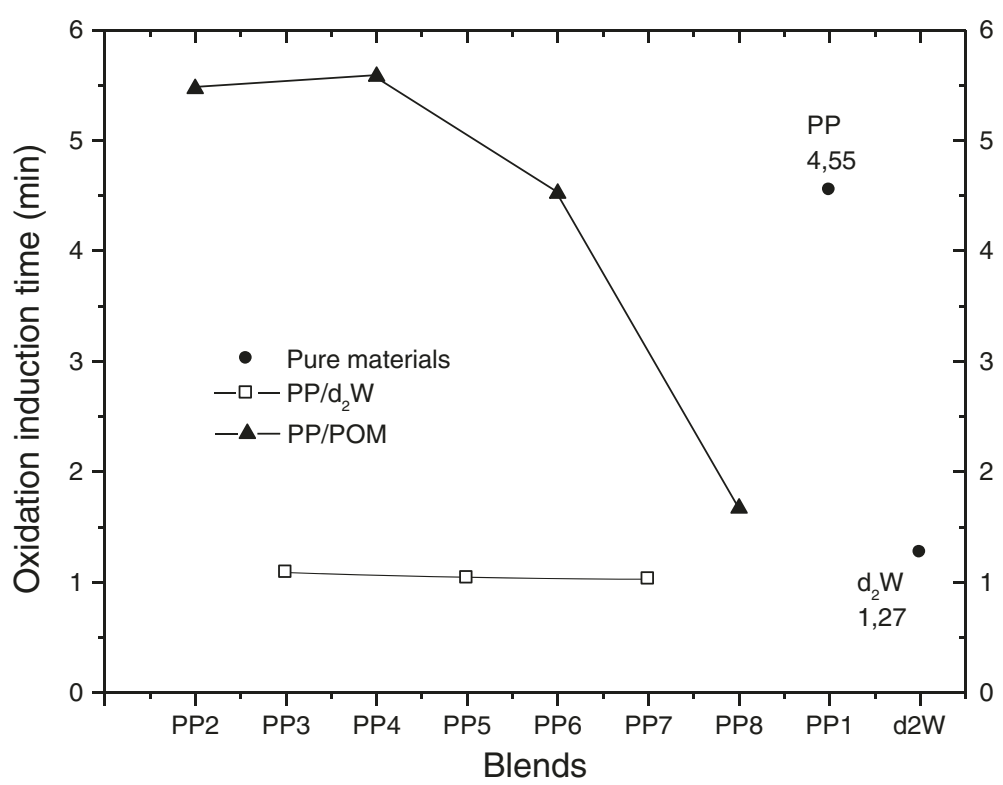

Figure 9 Oxidation induction time for pure materials and blends.

\section{Thermogravimetric analysis (TGA)}

Figure 10 shows the temperature for the onset of degradation (Ti) of the pure materials and blends. The variation in the $\mathrm{Ti}$ of blends compared to pure polypropylene may reflect the formation of volatile components and their diffusion in the polymeric matrix. The pure materials (POM and $\mathrm{d}_{2} \mathrm{w}^{\circ}$ ) had a lower Ti than polypropylene, with POM showing the lowest value. The Ti of the blends were not lower than those of POM and $\mathrm{d}_{2} \mathrm{w}^{\circ}$, except for blend $\mathrm{PP}_{8}$. The values of Ti varied with the concentration of $\mathrm{d}_{2} \mathrm{w}^{\circ}$ and POM in polypropylene. In the case of $\mathrm{d}_{2} \mathrm{w}^{\circ}$, increasing the concentration of the additive led to an increase in $\mathrm{Ti}$ and therefore had a stabilizing effect. This enhanced response can be attributed to the greater thermal stability of the vehicle for $\mathrm{d}_{2} \mathrm{w}^{\circ}$ relative to polypropylene. The MFI corroborated this stabilizing effect. Increasing the concentration of POM led to an increase in Ti up to the value seen with blend $\mathrm{PP}_{4}$, after which the Ti stabilized up to $\mathrm{PP}_{6}$ and then decreased in blend $\mathrm{PP}_{8}$.

Together, these results indicate that the addition of $\mathrm{d}_{2} \mathrm{~W}^{\circ}$ to polypropylene increased the thermal stability in a manner dependent on the concentration of additive. The low production of volatile components and the reduced mobility (diffusion capacity) of the polypropylene matrix

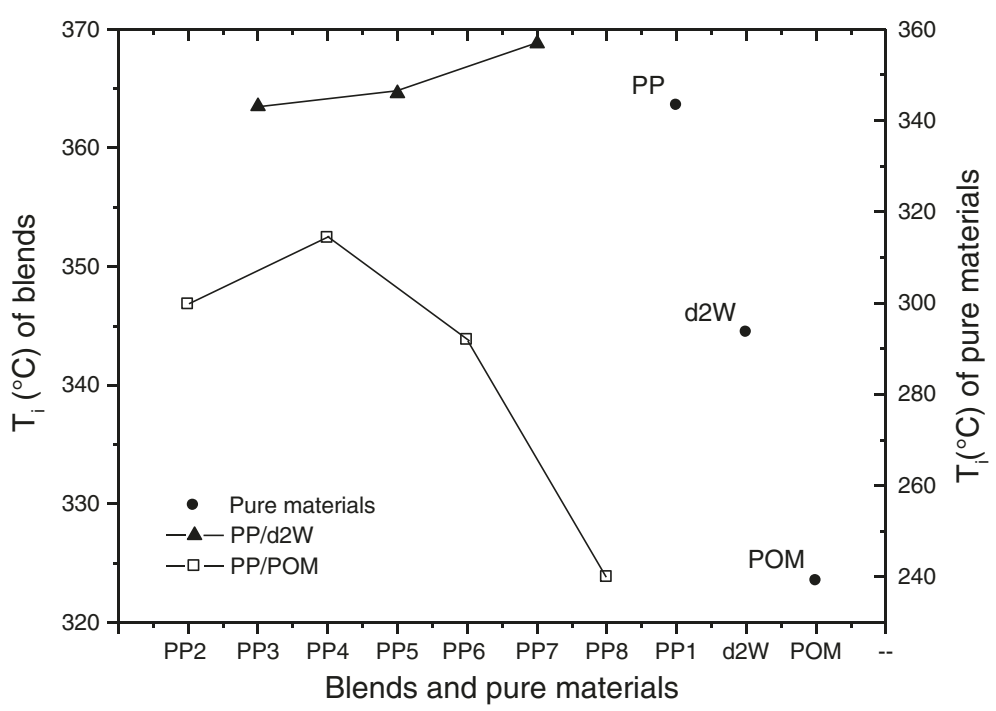

Figure 10 Onset degradation temperature $(\mathrm{Ti})$ determined at a rate of $10^{\circ} \mathrm{C} / \mathrm{min}$ for pure materials and blends. 


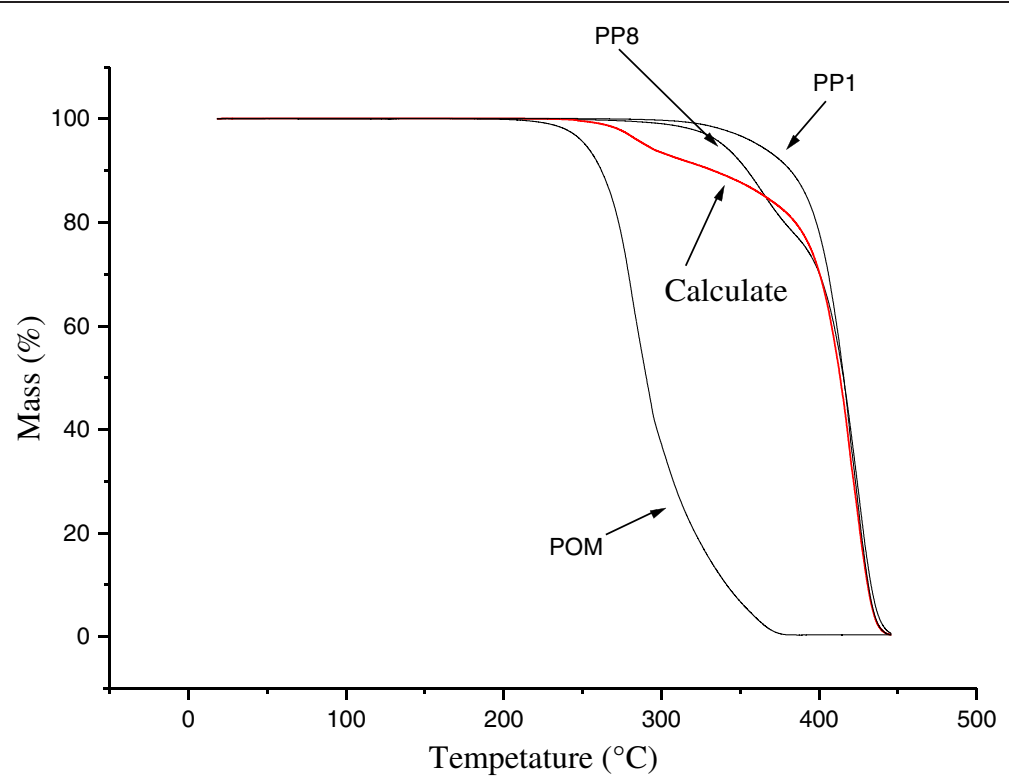

Figure 11 Experimental curves for changes in mass versus time for blend PP8 and pure materials (PP and POM). The theoretical (calculated) for blend PP8 is also shown.

Table 4 Activation energy (Ea) and correlation coefficients for pure materials and blends

\begin{tabular}{|c|c|c|c|c|c|c|c|}
\hline Blends & $\mathrm{PP}_{2}$ & $\mathrm{PP}_{3}$ & $\mathrm{PP}_{4}$ & $\mathrm{PP}_{5}$ & $\mathrm{PP}_{6}$ & $\mathrm{PP}_{7}$ & $\mathrm{PP}_{8}$ \\
\hline $\mathrm{Ea}\left(\mathrm{kJ} \cdot \mathrm{mol}^{-1}\right)$ & 152.6 & 110.3 & 145.5 & 175.9 & 128.8 & 182.8 & 58.2 \\
\hline r & -0.997 & -0.950 & -0.995 & -0.996 & -0.944 & -0.985 & -0.874 \\
\hline Pure materials & \multicolumn{2}{|c|}{ PP } & \multicolumn{2}{|c|}{ POM } & \multicolumn{3}{|c|}{$d_{2} w^{\circledast}$} \\
\hline $\mathrm{Ea}\left(\mathrm{kJ} \cdot \mathrm{mol}^{-1}\right)$ & \multicolumn{2}{|c|}{123.4} & \multicolumn{2}{|c|}{66.6} & \multicolumn{3}{|c|}{110.9} \\
\hline r & \multicolumn{2}{|c|}{-0.937} & \multicolumn{2}{|c|}{-0.880} & \multicolumn{3}{|c|}{-0.995} \\
\hline
\end{tabular}

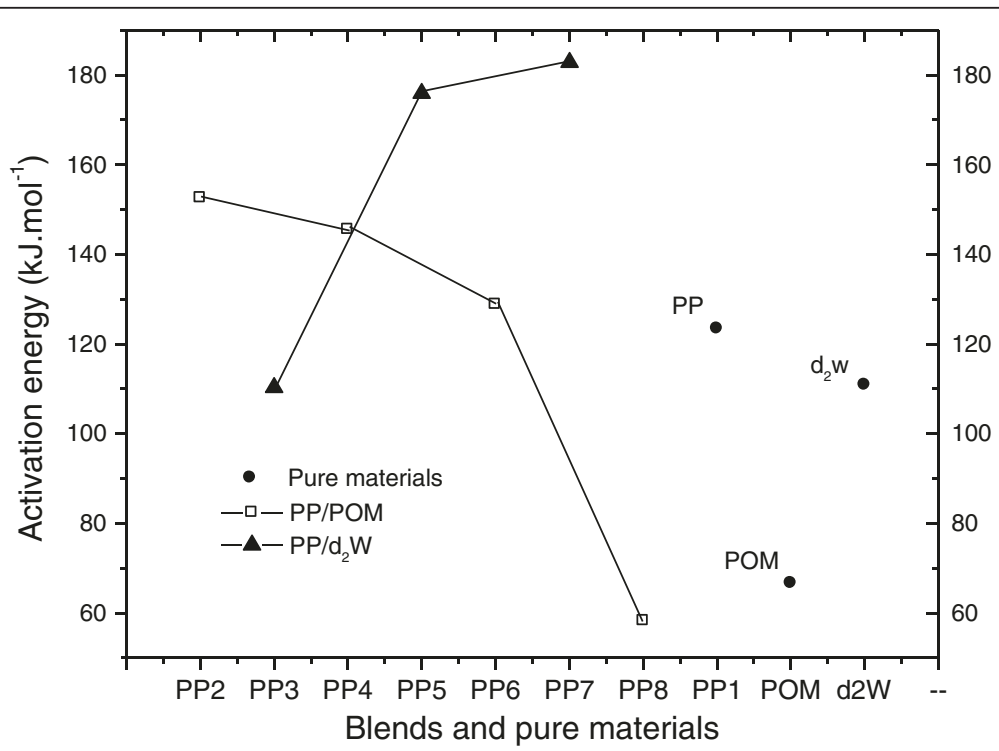

Figure 12 Energy of activation (Ea) for pure materials (PP, POM and $\left.d_{2} w^{\circledast}\right)$ and blends of PP/POM and PP/d $\mathbf{d}_{2} \mathbf{w}^{\odot}$. 
were probably important factors in this thermal stability. The addition of POM to polypropylene resulted in synergistic and antagonistic effects (stabilization and degradation), with the extent of stabilization and degradation depending on the amount of volatile components produced.

Figure 11 shows the change in mass as a function of temperature for blend $\mathrm{PP}_{8}$ and for the pure materials $\left(\mathrm{PP}_{1}\right.$ and $\mathrm{POM}$ ); a theoretical curve calculated curve calculated based on the weighted average of the experimental curves of the pure materials (PP and POM) is also shown. The region of the curve for blend $\mathrm{PP}_{8}$ close to the experimental curve of pure polypropylene $\left(\mathrm{PP}_{1}\right)$ may reflect a greater stabilizing effect of polypropylene. The stabilizing effect decreases as the loss of mass increases and the theoretical curve approximates the observed curve, probably because of competition with degradation reactions. The region beyond the point where the theoretical and observed curves cross corresponds to additional degradation by shifting the equilibrium of the degradation reactions of the matrix phase (PP) induced by the dispersed phase (POM).

Table 4 and Figure 12 show the energy of activation (Ea) of the pure materials and blends. Mixtures containing $\mathrm{d}_{2} \mathrm{w}^{\circ}$ and POM showed opposite changes in Ea as a function of the additive concentration in the polypropylene matrix. Ea may be regarded as the energy needed to cause the diffusion of one mole of atoms such that high Ea results in a relatively small diffusion coefficient (Callister 2006). In the blends studied here, the low mobility of pro-oxidant derivatives of $\mathrm{d}_{2} \mathrm{w}^{\circ}$ attached to a polymeric carrier material may have increased the concentration of additive thereby enhancing the Ea. For blends of PP/POM, the formation of volatile, low molecular mass products such as formaldehyde derived from POM could explain the decrease in Ea with increasing POM concentration. The propagation of oxidation at high temperatures in stabilized polypropylene involves the gas phase (Eriksson et al. 2002; Eriksson et al. 2001; Celina et al. 2006). Among the products generated by the degradation of PP, e.g., water, ethylene, isobutylene and acetic acid, formaldehyde is the one that most likely contributes to the propagation of oxidation via the gas phase in stabilized polypropylene (Eriksson et al. 2002). This conclusion agrees with the calculated curve for blend $\mathrm{PP}_{8}$ shown in Figure 10 that suggests a synergistic effect of degradation. The low Ea value for blend $\mathrm{PP}_{8}$ (lower than pure $\mathrm{POM}$ ) is also suggestive of synergism.

\section{Conclusion}

The addition of POM or $\mathrm{d}_{2} \mathrm{w}^{\circ}$ promoted the oxidative thermal degradation of polypropylene (PP), with the extent of degradation being regulated by the POM concentration in $\mathrm{PP} / \mathrm{POM}$ blends. At concentrations $<3 \%(\mathrm{w} / \mathrm{w}), \mathrm{POM}$ enhanced the thermal stabilization of polypropylene under the conditions investigated, whereas at concentrations $>3 \%$ POM stimulated the oxidation of polypropylene. These results suggest that the POM with a concentration $>3 \%$ $(\mathrm{w} / \mathrm{w})$, may act as a pro-oxidant agent of the PP, and the synergistic effect of degradation can be maximized by increasing the miscibility at the interface of the blend $\mathrm{PP} / \mathrm{POM}$.

\section{Competing interests}

The authors declare that they have no competing interests.

\section{Authors' contributions}

CLC carried preparation of the mixtures, analysis and drafted the manuscript. AFS carried melt flow index, mechanical properties and discussion of results. DSR has been involved in the analysis and interpretation of data and supervised the project. All authors read and approved the final manuscript.

\section{Acknowledgements}

The authors thank UFABC and CAPES for financial support and scholarships.

Received: 31 July 2013 Accepted: 9 October 2013

Published: 20 November 2013

\section{References}

Albertsson AC (1978) Biodegradation of synthetic polymers. II. A limited microbial conversion of ${ }^{14} \mathrm{C}$ in polyethylene to ${ }^{14} \mathrm{CO}_{2}$ by some soil fungi. J Appl Polym Sci 22:3419-3433

Albertsson I (2003) Evaluation of degradability of biodegradable polyethylene (PE). Polym Degrad Stabil 80:39-43

Gröning M, Hakkarainen G, Albertsson A-C (2008) Quantitative Determination of Volatiles in Polymers and Quality Control of Recycled Materials by Static Headspace Techniques. In: Albertsson A-C, Hakkarainen M (eds) Chromatography for Sustainable Polymeric Materials Renewable, Degradable and Recyclable, Vol (Eds). Springer, Berlin Heidelberg, pp 51-84

ASTM D-1238-04 (2004) Standard Test Method for Melt Flow Rates of Thermoplastics by Extrusion Plastometer, Annual Book of ASTM. American Society for Testing and Materials, Philadelphia, PA

ASTM D638-10 (2010) Standard test method for tensile properties of plastics. American Society for Testing and Materials, Philadelphia, PA

ASTM E1641 - 07 (2007) Standard Test Method for Decomposition Kinetics by Thermogravimetry. American Society for Testing and Materials, Philadelphia, PA

Babetto AC, Canevarolo SV (2002) Effect of the screw element from the degradation of polypropylene during multiple extrusions. Adv Polym Tech 21:243-249

Bouhelal SM, Cagiao ME, Bartolotta A, Marco GD, Garrido L, Benachour D, Calleja FJB (2010) On Polyethylene Chain Generation Through Chemical Crosslinking of Isotactic Polypropylene. J Appl Polym Sci 116:394-403

Cáceres CA, Canevarolo SV (2009) Degradation of polypropylene during the extrusion and generation of volatile organic compounds. Polímeros: Ciência e Tecnologia 19:79-84

Canevarolo SVJ (ed) (2003) Techniques for polymer characterization. São Paulo, Ed Artliber, Brasil

Callister WD Jr (2006) Materials Science and Engineering: An Introduction, 2nd edn. LTC, Rio de Janeiro, p 125.19

Celina M, George GA (1993) A heterogeneous model for the thermal oxidation of solid polypropylene from chemiluminescence analysis. Polym Degrad Stabil 40:323-335

Celina M, George GA (1995) Heterogeneous and homogeneous kinetic analyses of the thermal oxidation of polypropylene. Polym Degrad Stabil 50:89-99

Celina M, Clough RL, Jones GD (2006) Initiation of polymer degradation via transfer of infectious species. Polym Degrad Stabil 91:1036-1044

Cottin H, Gazeau MC, Doussin JF, Raulin F (2000) An experimental study of the photodegradation of polyoxymethylene at 122, 147 and $193 \mathrm{~nm}$. J Photoch Photobio A 135:53-64

De Paoli MA (2008) Degradation and Stabilization of Polymers. Chemkeys, Brasil

Duan Y, Li H, Ye L, Liu X (2006) Study on the Thermal Degradation of Polyoxymethylene Thermogravimetry-Fourier transform infrared spectroscopy (TG-FTIR). J Appl Polym Sci 99:3085-3092

Eriksson P, Reitberger T, Ahlblad G, Stenberg B (2001) Oxidation fronts in the polypropylene studied by imaging chemiluminescence. Polym Degrad Stabil 1:73:177 
Eriksson P, Reitbergerb T, Stenberga B (2002) Gas-phase Contribution to the spreading of oxidation in the polypropylene studied by imaging chemiluminescence. Polym Degrad Stabil 78:183-189

European Bioplastics position paper (2012) comments on the study. "A Life Cycle Assessment of Oxo-biodegradable, Compostable Bags and Conventional" (May 2012, Intertek)., http://www.google.com.br/url?sa=t\&rct=j\&q=\&esrc=s\&source= web\&cd=1\&ved=0CCsQFjAA\&url=http\%3A\%2F\%2Fen.european-bioplastics.org\% 2Fwp-content\%2Fuploads\%2F2012\%2F07\%2FPositionspaper_LCA_160712.pdf\&ei= ZANYUrK9DIWK9QSmnoG4Cw\&usg=AFQjCNFGgdl3B6DDIGeKTUerJXsZW8 SlUw\&bvm=bv.53899372,d.eWU\&cad=rja. Accessed 15 Jan 2013

Gahleitner M (2011) Editorial corner - a personal view. Polyolefins for the 21st century. Express. Polymer Letters 5:936

Garton A, Carlsson DJ, Wiles DM (1978) Role of polymer morphology in the oxidation of polypropylene. J Polym Sci Pol Chem 16:33-40

Groening M, Hakkarainen M (2002) Headspace solid-phase microextraction with gas chromatography/mass spectrometry reveals a correlation between the degradation product pattern and changes in the mechanical properties during the thermooxidation of in-plant recycled polyamide 6.6. J Appl Polym Sci 86:3396-3407

Huang JM, Cheng HJ, WU JS, Chang FC (2003) Blends of poly(propylene) and polyacetal compatibilized by ethylene vinyl alcohol copolymers. J Appl Polym Sci 89:1471-1477

Kale G, Kijchavengkul T, Auras R, Rubino M, Selke SE, Singh SP (2007) Compostability of bioplastic packaging materials: an overview. Macromol Biosci 7:255-277

Kim BK (1996) Reactive Extrusion of Polyolefins and their Blends. Korea Polym J 4:215-226

Kumar G, Neelakantan NR, Subramanian N (1995) Polyacetal and toughened thermoplastic polyurethane polyacetal elastomer: crystallinity and fracture mechanics. J Mater Sci 30:1480-1486

PlasticsEurope (2011) An Analysis of European Plastics Production, demand and recovery for 2010., http://www.plasticseurope.org/Document/plastics-thefacts-2011.aspx, accessed 19/03/2012

Rabello MS, White JR (1997) The role of physical structure and morphology in the photo degradation behaviour of polypropylene. Polym Degrad Stabil 56:55-73

Rocha MCG, Coutinho FMB, Balke S (1994) Controlled degradation of polypropylene. Polímeros: Ciência e Tecnologia 4:16-22

Roy PK, Surekha P, Rajagopal C, Choudhary V (2007) Thermal degradation studies of LDPE containing cobalt. Express Polymer Letters 1:208-216

Wang X, YU W, Nie Q, Guo Y, DU J (2011) A real-time study on the evolution of the degradation of polypropylene during mixing process. J Appl Polym Sci 121:1220-1243

Waldman WR, De Paoli MA (1998) Thermo-mechanical degradation of polypropylene, low-density polyethylene and their 1:1 blend. Polym Degrad Stabil 60:301-308

doi:10.1186/2193-1801-2-623

Cite this article as: de Carvalho et al:: A study of the controlled

degradation of polypropylene containing pro-oxidant agents. SpringerPlus 2013 2:623.

\section{Submit your manuscript to a SpringerOpen ${ }^{\odot}$ journal and benefit from:}

- Convenient online submission

- Rigorous peer review

- Immediate publication on acceptance

- Open access: articles freely available online

- High visibility within the field

- Retaining the copyright to your article

Submit your next manuscript at $>$ springeropen.com 